\title{
Evaluation of complications during third stage of labour among women delivering at tertiary care center
}

\section{Tanya Agarwal, Ruchi Kalra*, Aabha Suryavanshi} Department of Obstetrics and Gynaecology, People's College of Medical Sciences and Research Center, Bhopal,
Madhya Pradesh, India

Received: 14 April 2018

Accepted: 08 May 2018

\section{*Correspondence:}

Dr. Ruchi Kalra,

E-mail: drruchi.kalra15@gmail.com

Copyright: (C) the author(s), publisher and licensee Medip Academy. This is an open-access article distributed under the terms of the Creative Commons Attribution Non-Commercial License, which permits unrestricted non-commercial use, distribution, and reproduction in any medium, provided the original work is properly cited.

\section{ABSTRACT}

Background: The common complications occurring during third stage of labor are PPH Retained Placenta, Morbid adherent placenta- placenta accreta, placenta increta, percreta, perineal tears, uterine inversion increasing the maternal morbidity and mortality. The objective of the present study was to evaluate percentage and spectrum of obstetrics complication occurring during third stage of labor.

Methods: An observational study was done at Department of Obstetrics and Gynecology, People's College of Medical Sciences and Research Center, Bhopal from January 2016 to December 2017. All women delivering vaginally including instrumental deliveries were included. The medio-lateral episiotomy was given to all primigravida and for multigravida decision was case based as big size babies, instrumental deliveries, rigid perineum. Active management of third stage of labor was practiced.

Results: 899 women delivered vaginally during the study period of 2 years (Jan -Dec 2016 Jan -Dec 2017). Among these $6.45 \%$ (58 women) had various complications during third stage of labor . 55\% were primigravida. Complications which were observed to occur during third stage of labor were perineal tear 4\% (37/899 deliveries). Atonic PPH occurred in 0.5\% (9/899 deliveries) Traumatic PPH was in 1.44\% (13/899 deliveries and $0.3 \%$ cases had retained placenta. Associated condition in perineal tear cases were $92 \%$ had big size babies $5 \%$ cases were preterm labor and in $3 \%$ cases ventouse application was done.

Conclusions: Common complications were 1 st and 2 nd degree perineal tears occurred in $4 \%$ deliveries and traumatic $\mathrm{PPH}$ were in $1.44 \%$ of cases.

Keywords: Perineal tears, PPH, Third stage complications

\section{INTRODUCTION}

"Medicine is a science of uncertainty and an art of probability, William Osler.”

This statement of Sir William Osler is also very true for the labor cases as uncertainties prevail till the last and even after delivery of baby. The complications can occur even in the third stage of labor. The third stage of labor starts after expulsion of fetus and continues till expulsion of placenta. It can be sub categorized as phase of separation and phase expulsion of placenta. The average time of third stage is $15 \mathrm{~min} .^{1}$

The common complications occurring during third stage is Retained Placenta (prolonged third stage) which is failure to deliver placenta within 30 minutes using active management of 3rd stage and 60 minutes by physiological management. The incidence of retained placenta is $2 \%$ at term and markedly increases during preterm. Retained placenta can be either trapped placenta or adherent placenta. 
Adherent Placenta is total or partial failure of separation of placenta. Morbidly adherent placenta is invasion of chorionic villi due to primary or secondary deficiency of decidua basilis.

There are three types according to depth of invasion of myometrium -placenta accreta, placenta increta, placenta percreta. The incidence of percreta increasing due to increasing cesarean section rate. ${ }^{2}$ Postpartum Haemorrhage is a common complication of delivery and most common cause of maternal deaths accounting for $35 \%$ of maternal deaths worldwide. These young deaths are devastating to the lives of families and their children.

Postpartum hemorrhage, is defined as more than $500 \mathrm{ml}$ following vaginal delivery or $1000 \mathrm{ml}$ of blood loss following caesarean section in the first 24 hours following delivery.

PPH may occur due to failure of uterus to contract adequately (atonicity), genital tract trauma either cervical or vaginal lacerations and tears, uterine rupture, retained placental tissue and maternal bleeding disorders.

About 830 women die from pregnancy or childbirth related complications everyday all over the world. In $52 \%$ of cases, the cause of death is three leading causes hemorrhage, sepsis and hypertensive disorders. As per WHO $25 \%$ of the maternal deaths are due to PPH. Postpartum Hemorrhage is the quickest maternal killer, can even kill healthy mother within 2 hours if not treated.

Incidence of PPH is reported as $2-4 \%$ after vaginal delivery and $6 \%$ after cesarean delivery. Uterine atony being the cause in $50 \%$ of cases. Every year 14 million women suffer from PPH. ${ }^{3}$ Estimates of maternal mortality ratio in India done by Indian Council of Medical Research in 2003 also reported PPH as the leading cause of maternal mortality in study population. Lower birth canal trauma is classified as periuretheral, periclitorial, cervical lacerations, vaginal lacerations, para-vaginal haematoma and perineal lacerations.

Uterine inversion is the condition when uterus turns inside out. It is the folding of the fundus into the uterine cavity in varying degree. Incomplete when fundus of the uterus has turned inside out but inverted fundus has not descended through cervix and complete when the inverted fundus has passed completely through cervix to lie within the vagina or lie often outside the introitus. It is a rare complication occurring during third stage of labor reported to occur in 1 in 2000 to 1 in 6000 cases.

Present study was done to evaluate complications during third stage of labor in women delivering at Tertiary Health Care Centre.

The aim of this study was to evaluate the percentage and various spectrum of obstetrics complication occurring in women during third stage of labor.

\section{METHODS}

A prospective observational study was carried out at Department of Obstetrics and Gynecology, of People's Hospital associated to People's College of Medical Sciences and Research Center, Bhopal (M.P) from January 2016 to December 2017. After obtaining Institutional Research and Ethics Committee approval, all women delivering vaginally at the hospital during the study period were included in the study after obtaining their written informed consent.

\section{Inclusion criteria}

Vaginal deliveries and instrumental vaginal deliveries (ventouse or forceps application).

\section{Exclusion criteria}

Deliveries by caesarean sections.

The medio-lateral episiotomy was given during the crowning stage of labor as a routine practice for all primigravidas and for multigravida decision was case based as given in big size babies, instrumental deliveries, rigid perineum. The third stage of labor was the duration from the delivery of the baby until delivery of the placenta.

Active management of third stage of labour (AMTSL) was practiced in all laboring women. Uterotonic medication administered after delivery of baby, late cord clamping (> $60 \mathrm{sec}$ of birth) and cutting of umblical cord and controlled cord traction until separation and delivery of the placenta.

Administration of uterotonic drug (oxytocin 10units in Ringer Lactate) was drug of choice. In addition, other drugs given if required were methyl ergometrine $0.2 \mathrm{mg}$ iv or im, misoprostol $600 \mu \mathrm{g}$ per rectal was used. Controlled and gentle cord traction application was applied for delivery of placenta. Fundal massage after delivery of placenta was done. Uterine palpation and observation of vitals and bleeding per vaginum done for delivered patient for 2 hours after placental delivery.

\section{RESULTS}

899 women delivered vaginally during the study period of 2 years (Jan -Dec 2016 Jan -Dec 2017). Among these $6.45 \%$ (58 women) had various complications during third stage of labor (Figure 1).

Complications which were observed to occur during third stage of labor were perineal tear 4\% (37/899 vaginal deliveries). Atonic PPH occurred in $0.5 \%$ (9/899 vaginal deliveries). Traumatic PPH was $1.44 \%$ (13/899 vaginal deliveries and $0.3 \%$ (3/899 vaginal deliveries) had retained placenta (Figure 2 ). 


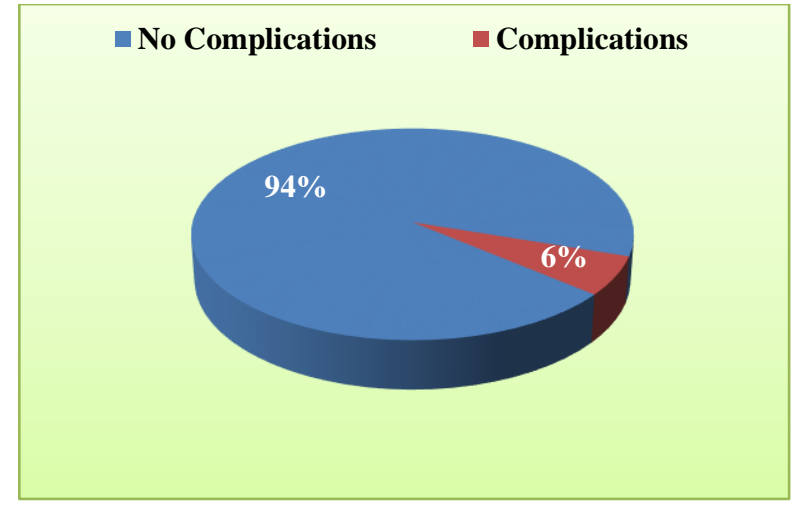

Figure 1: Third stage complication.

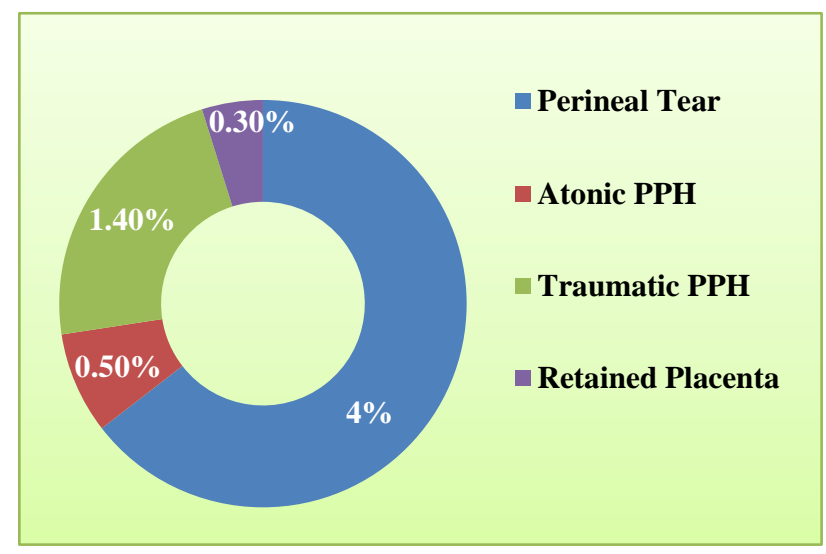

Figure 2: Spectrum of third stage complications.

Complications which were observed to occur during third stage of labor were perineal tear 4\% (37/899 deliveries). Atonic PPH occurred in $0.5 \%$ (9/899 deliveries) Traumatic PPH was $1.44 \%$ (13/899 deliveries) and $0.3 \%$ cases had retained placenta (Figure 3 ).

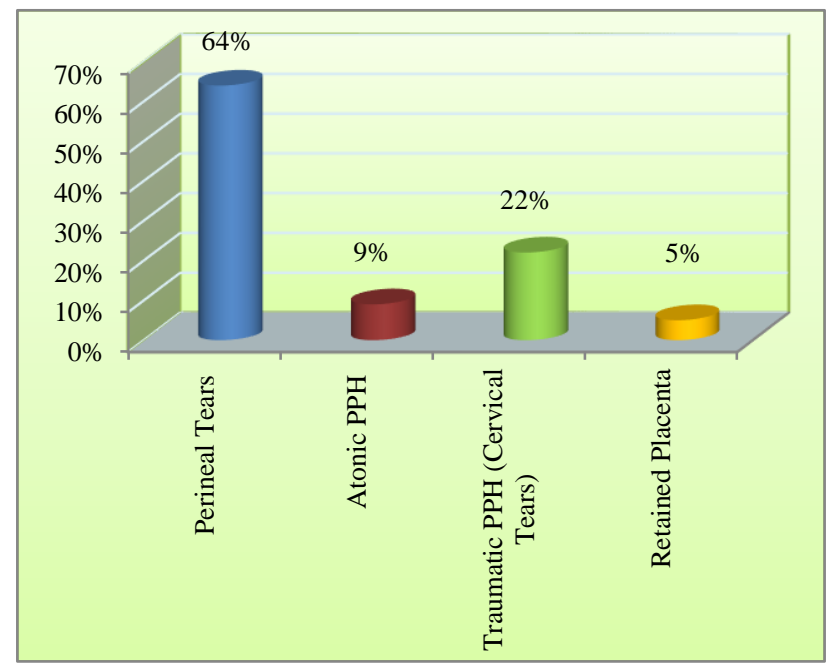

Figure 3: Percentage distribution of third stage complications.

The 58 women having third stage complications were analyzed for their Age Distribution 7\% (4 women) were
$<20$ years, $40 \%$ (23 women) were between 21-24years, $31 \%$ (18) were between 25-30 years and 22\% (13) women were above $30 y e a r s$ of age (Figure 4 ).

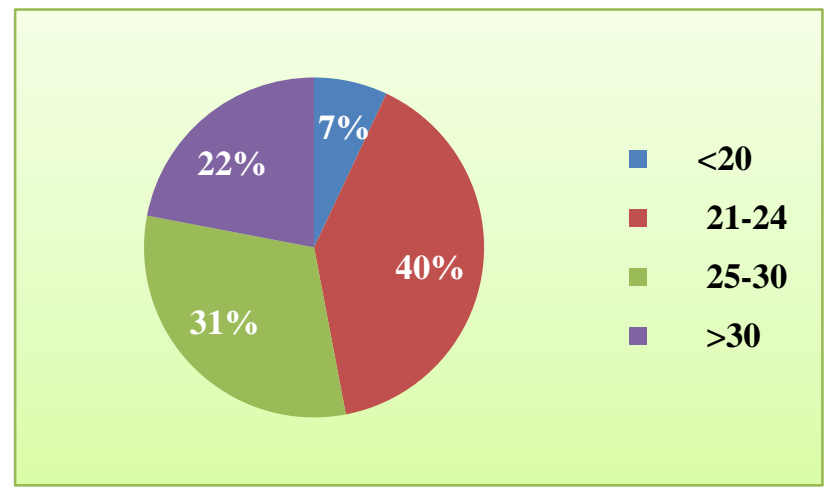

Figure 4: Age distribution of women with third stage complication.

The labouring women with third stage complications they were also analyzed for their parity. Of 58 delivered women, highest percentage was $55 \%$ of Primigravida (32 women) $36 \%$ (21) were multigravida and 9\% (5 women) were grand multipara (Figure 5).

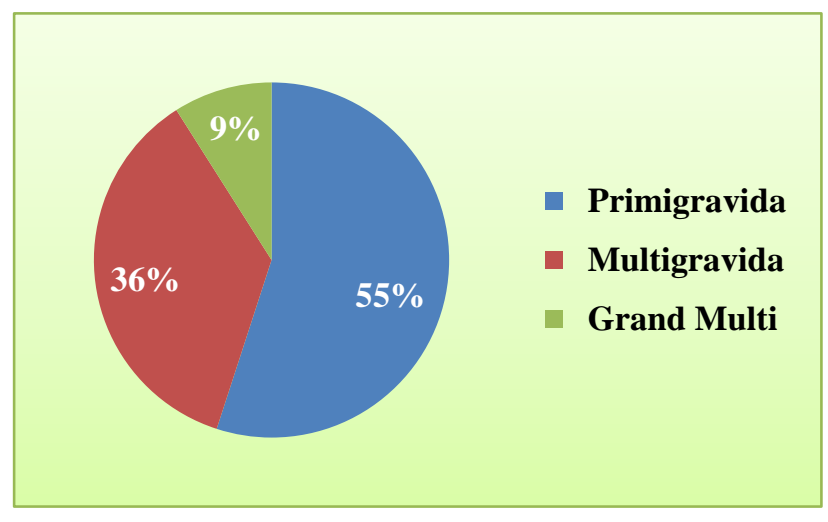

Figure 5: Parity distribution of cases.

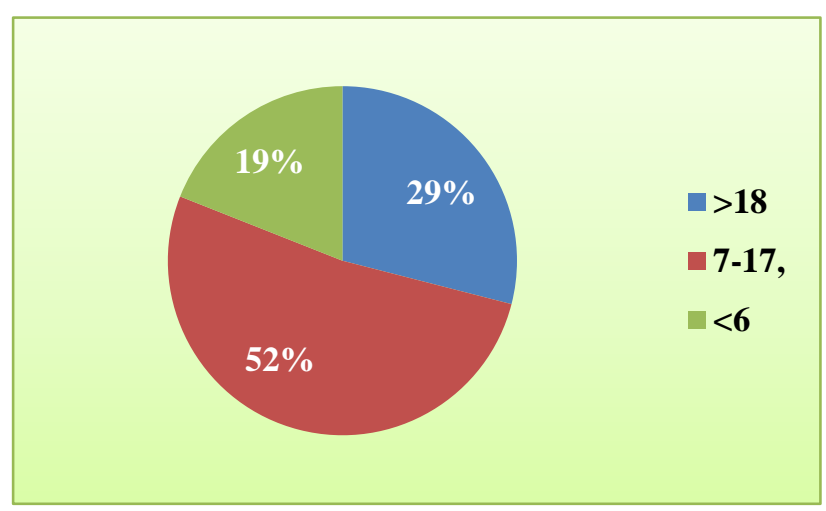

Figure 6: Duration of labor in hours.

Duration of labor in these 58 cases were also analyzed. In the study, 29\% (17 women) labor duration was 18 hours, $52 \%$ (30 women) had labor duration between 7 to 17 
hours and $19 \%$ (11 women) delivered in less than 6 hours (Figure 6).

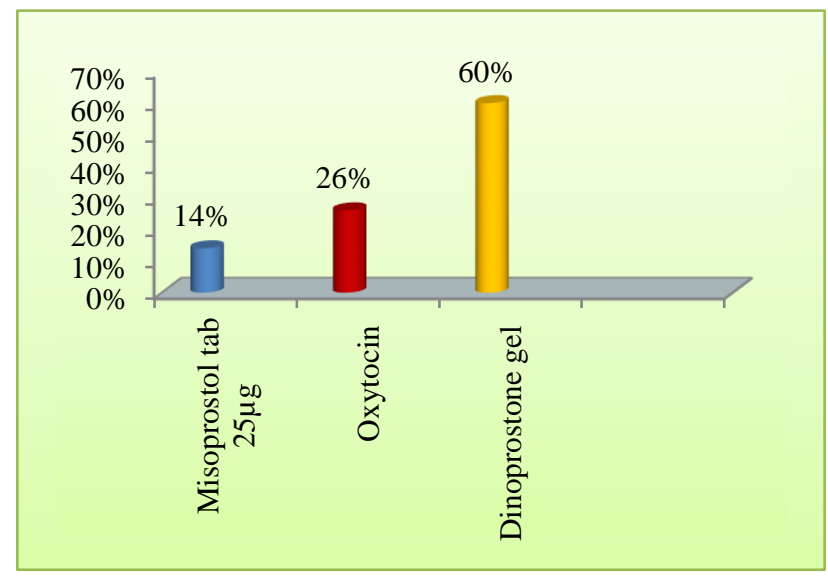

Figure 7: Mode of Induction.

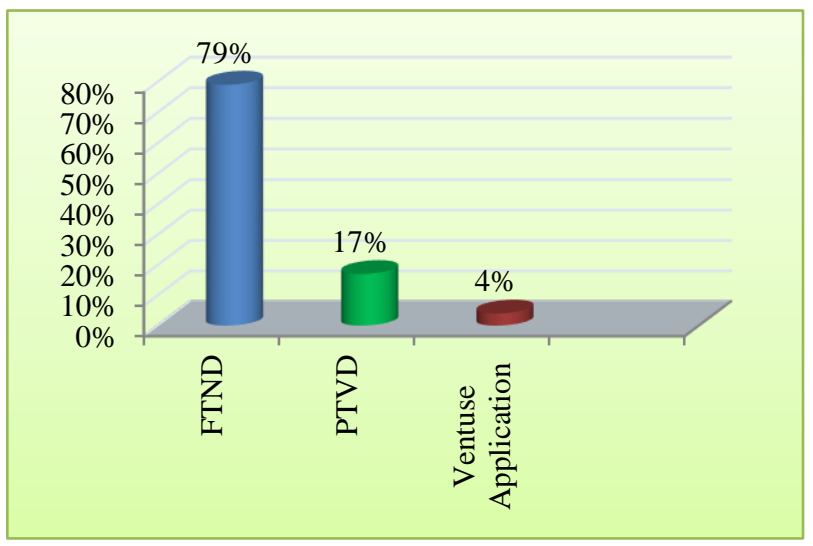

Figure 8: Mode of Delivery.
Mode of Induction was also analyzed. Of 58 cases having complications, $14 \%$ ( 8 women) were induced by $25 \mu \mathrm{g}$ Misoprostol tab, 26\% (15 women) were induced by Oxytocin and $60 \%$ (35 women) by dinoprostone gel (Figure 7).

Out of 58 vaginal deliveries, $79 \%$ (46 women) were full term, $17 \%$ (10 women) were preterm, 4\% (2 women) delivered were VBAC (Figure 8).

The commonest complication observed was perineal tear which occurred in $64 \%$ cases. All the tears were 1 st and 2nd degree tear. They were repaired immediately under anesthesia.

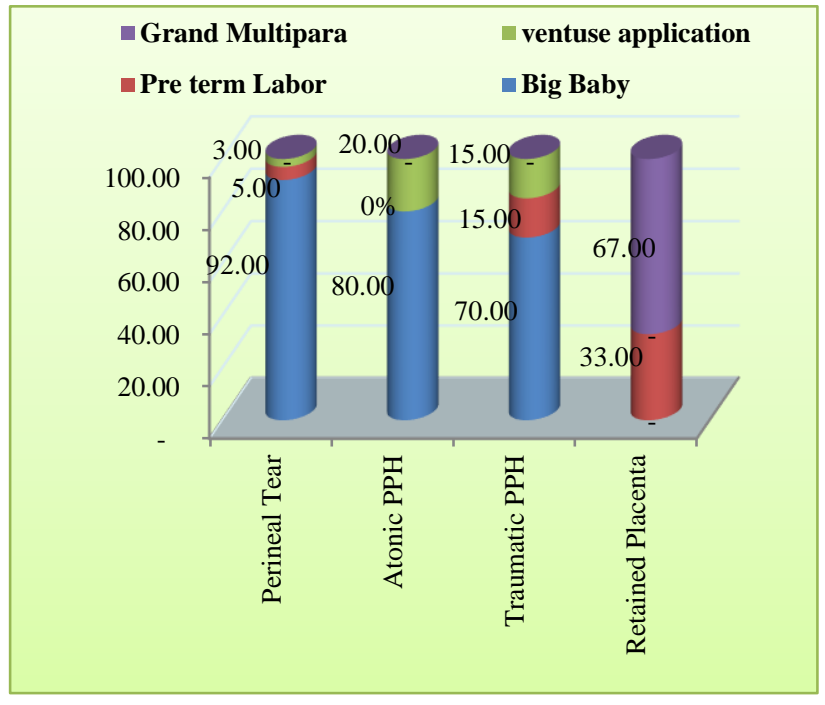

Figure 9: Associated conditions.

Table 1: Overall spectrum of complications with associated conditions contributing to complications.

\begin{tabular}{|c|c|c|c|c|c|c|}
\hline Complications & $\begin{array}{l}\text { Percentage } \\
\mathbf{n - - 5 8}\end{array}$ & $\begin{array}{l}\text { Over All } \\
\text { contributing } \\
\text { percentage of } \\
\text { complications } \\
\text { N-899 }\end{array}$ & $\begin{array}{l}\text { Associated } \\
\text { conditions }\end{array}$ & Percentage & Management & Percentage \\
\hline Perineal tear & $64 \%(37)$ & $\begin{array}{l}4 \% \\
(37 / 899)\end{array}$ & $\begin{array}{l}\text { Big baby } \\
\text { Preterm labor } \\
\text { Instrumental }\end{array}$ & $\begin{array}{l}92 \%(34) \\
5 \%(2) \\
3 \%(1)\end{array}$ & $\begin{array}{l}\text { Tear repair } \\
\text { Conservative }\end{array}$ & $\begin{array}{l}46 \%(27) \\
34 \%(20)\end{array}$ \\
\hline $\begin{array}{l}\text { Postpartum } \\
\text { hemorrhage-atonic } \\
\text { uterus }\end{array}$ & $9 \%(5)$ & $\begin{array}{l}0.5 \% \\
(5 / 899)\end{array}$ & $\begin{array}{l}\text { Big size baby } \\
\text { Ventuse Delivery }\end{array}$ & $\begin{array}{l}80 \%(4) \\
20 \%(1)\end{array}$ & $\begin{array}{l}\text { Conservative } \\
\text { Hysterectomy }\end{array}$ & $\begin{array}{l}80 \%(4) \\
20 \%(1)\end{array}$ \\
\hline $\begin{array}{l}\text { Post partum } \\
\text { hemorrhage -traumatic } \\
\text { cause -cervical tear }\end{array}$ & $22 \%(13)$ & $\begin{array}{l}1.44 \% \\
(13 / 899)\end{array}$ & $\begin{array}{l}\text { Big baby } \\
\text { Preterm labor } \\
\text { Ventuse delivery }\end{array}$ & $\begin{array}{l}70 \%(9) \\
15 \%(2) \\
15 \%(2)\end{array}$ & $\begin{array}{l}\text { Cervical } \\
\text { exploration \& } \\
\text { Tear repair }\end{array}$ & $22 \%(13)$ \\
\hline Retained placenta & $5 \%(3)$ & $0.3(3 / 899)$ & $\begin{array}{l}\text { Grand multi para } \\
\text { Pre term labor }\end{array}$ & $\begin{array}{l}67 \%(2) \\
33 \%(1)\end{array}$ & $\begin{array}{l}\text { Manual } \\
\text { removal of } \\
\text { placenta }\end{array}$ & $5 \%(3)$ \\
\hline $\begin{array}{l}\text { Morbidly adherent } \\
\text { placenta }\end{array}$ & 0 & nil & ----- & ---- & -------- & ------ \\
\hline Uterine inversion & 0 & nil & ------ & ----- & ------- & ------ \\
\hline
\end{tabular}


There was no incidence of $3^{\text {rd }}$ or $4^{\text {th }}$ degree perineal tear during study period. Associated condition were $92 \%$ (34 cases) had big size babies (weight $>3.5 \mathrm{~kg}$ ), $5 \%$ ( 2 cases) cases had preterm labor and in $3 \%$ cases ventouse application was done. 9\% cases had atonic PPH $80 \%$ (4 cases) had big size baby and $20 \%$ cases ventuse delivery. $80 \%$ were managed conservatively using uterotonic medicines where as in 1 case (20\%) obstetric hysterectomy was done. $22 \%$ of cases had cervical tears.

All cases were explored under anesthesia and repaired using vicryl 1.0 sutures. On analyzing associated conditions $70 \%$ cases had big babies, $15 \%$ had Pre-Term labor and $15 \%$ had ventuse delivery.

$5 \%$ of women had retained placenta for where manual removal was done. There were no cases with Uterine inversion and Morbidly Adherent placenta (Figure 9).

Table 1 is summary showing overall spectrum of complications with associated conditions contributing to complications.

\section{DISCUSSION}

In present study, 58 patients had various complications during third stage of labor. They were evaluated for the spectrum of complications and the associated conditions.

In the study the perineal tear was the commonest complications occurring in highest percentage $(64 \%)$ of cases. All had $1^{\text {st }}$ and $2^{\text {nd }}$ degree tears and were repaired immediately using suture vicryl 1.0 RB. Associated conditions were $92 \%$ (34 cases) had big size babies (weight $>3.5 \mathrm{~kg}$ ), $5 \%$ (2 cases) cases had preterm labor and in $3 \%$ cases ventouse application was done.

In study published by Ott $\mathbf{J}$, perineal laceration incidence was $26.2 \%$ upon univariate analysis maternal age, gestational age at delivery, birth weight and head circumference were positively co-related with perineal laceration. $^{7}$ In their study they stated that individual midwife who delivered the child was a significant influencing factor. This study suggests further exploration on individual basis.

Smith LA et al in their large prospective study found no evidence for an association between use of a birth pool, maternal position for delivery and digital perineal stretching during the second stage of labor with OASIS (Obstetric anal sphincter injury) or any other spontaneous perineal trauma. ${ }^{8}$ They also found a low over all incidence of OASIS and fewer second degree tears were sutured in the community compared with hospital setting.

The study confirms previous findings of overall high incidence of perineal trauma following vaginal delivery and a strong association between forceps delivery and perineal trauma. In present study first and second degree perineal tears contributed maximaly $(64 \%)$ to overall third stage complications but no case of third or fourth degree perineal tear occured.

Suto $\mathrm{M}$ found that a total of 1881 pregnant women had initial antenatal care at one of the 3 study sites. ${ }^{9}$ Of these, 1521 were eligible for inclusion. Intact perineum rates were $49.5 \%(209 / 422)$ and $69.9 \% \quad(768 / 1099)$ in nulliparous and multiparous women, respectively.

First-degree lacerations occurred in $36.7 \%$ (155/422) of nulliparous women and $27.1 \%$ (298/1099) of multiparous women, and second-degree lacerations occurred in $13.5 \%$ (57/422) of nulliparous women and 3.0\% (33/1099) of multiparous women. One multiparous woman experienced a third-degree laceration $(0.1 \%)$.

No women suffered fourth-degree or cervical lacerations. Logistic regression analyses showed that older age $(\geq 35$ years), the hands-and-knees position, and using a birthing chair during birth increased the risk of perineal laceration both in nulliparous and in multiparous women. In addition, waterbirths increased the risk of perineal laceration in multiparous women.

Schimtz et al reported in their study instrumental delivery, nulliparity, persistent posterior orientation and increased birth weight as independently associated with severe perineal lacerations. ${ }^{10}$ Restrictive use of mediolateral episiotomy protects against severe perineal lacerations especially in case of instrumental delivery.

Hsieh WC et al reported that they analyzed 1879 women who underwent vaginal deliveries assisted by midline episiotomy at a tertiary hospital. ${ }^{11}$ Obstetric risk factors were analyzed for women with and without third- and fourth-degree lacerations. They concluded that with regard to severe perineal lacerations during vaginal delivery, there are multiple obstetric contributory factors despite routine episiotomy, among them, nulliparity, longer labor duration, greater newborn head circumference, and instrument-assisted vaginal delivery. The latter should only be performed after careful evaluation.

Aasheim $\mathrm{V}$ et al published in Cochrane review that moderate-quality evidence suggests that warm compresses, and massage, may reduce third- and fourthdegree tears but the impact of these techniques on other outcomes was unclear or inconsistent. ${ }^{12}$ Poor-quality evidence suggests hands-off techniques may reduce episiotomy, but this technique had no clear impact on other outcomes. There were insufficient data to show whether other perineal techniques result in improved outcomes. Further research could be performed evaluating perineal techniques, warm compresses and massage, and how different types of oil used during massage affect women and their babies. It is important for any future research to collect information on women's views. 
Ngwenya S reported that the incidence of PPH was $1.6 \%$ during study period. ${ }^{13}$ The most identifiable risk factor was pregnancy induced hypertension followed by prolonged labor. The uterine atony was the most common cause of post-partum hemorrhage. In present study in $0.5 \%$ cases atonic PPH occurred, $1.4 \%$ cases were traumatic PPH. At present set up, active management of third stage is a routine practice hence percentage of atonic PPH cases were less.

As per the WHO Recommendations for the prevention and treatment of postpartum hemorrhage, the strong recommendations having moderate quality evidence are:

- The use of uterotonics for the prevention of PPH during third stage of labour is recommended for all births.

- Oxytocin (10 U IV or IM) is recommended uterotonic drug for prevention of $\mathrm{PPH}$.

- In settings where oxytocin is unavailable the use of other injectable uterotonic drugs (if appropriate ergometrine /methyl ergometrine) or the fixed drug combination of oxytocin and ergometrine or oral misoprostol $600 \mu \mathrm{g}$ is recommended.

- In settings where skilled birth attendants are not present, and oxytocin is unavailable, the administration of misoprostol $600 \mu \mathrm{g}$ by community health care worker or lay worker is recommended for the prevention of PPH.

- Late cord clamping (performed after 1-3 minutes) are recommended for all births while initiating simultaneous essential new born care.

- Early cord clamping (<1minute of birth) is not recommended unless the baby is asphyxiated and needs to be moved early for resuscitation.

- Postpartum abdominal uterine tonus for early identification of uterine atony is recommended for all women

- Intravenous oxytocin alone is the recommended oxytonic drug for the treatment of PPH.

- If intravenous oxytocin is unavailable or if the bleeding does not respond to oxytocin or ergometrine or fixed dose oxytocin ergometrine or a prostaglandin drug including sublingual misoprostol $800 \mu \mathrm{g}$ is recommended.

- The use of isotonic crystalloids is recommended in preference to colloids for the initial intravenous fluid resuscitation of women with $\mathrm{PPH}$.

- Uterine massage is recommended for treatment of PPH.

- If bleeding does not stop in spite of using uterotonics and other conservative interventions (uterine massagae or balloon tamponade) then surgical intervention is recommended.

In the present study 3 of 58 cases ( $5 \%$ cases) had retained placenta.
The WHO Guide, managing complications in pregnancy and childbirth states that if placenta is not expelled within 30 minutes after delivery of the baby, the women should be diagnosed as having retained placenta. ${ }^{15}$ Since there is no evidence for or against this definition, the delay use to diagnose this condition is left to the judgment of clinician.

The same guide also recommends that, in the absence of hemorrhage, the woman should be observed for a further 30 minutes following the initial 30 minutes, before manual removal of the placenta is attempted.

The consultation noted that, in the absence of bleeding, spontaneous expulsion of the placenta can still occur; thus, a conservative approach is advised and the timing of manual removal as the definitive treatment is left to the judgment of the clinician. The recommendation about prostaglandin E2 is based on the lack of evidence, as well as concerns regarding adverse events, notably cardiac events.

Should intra-umbilical vein injection of oxytocin with or without Intraumbilical vein injection of oxytocin with saline may be offered for the management of retained placenta. (Quality of evidence: moderate. Strength of recommendation: weak.)

If, in spite of controlled cord traction, administration of uterotonics and intraumbilical vein injection of oxytocin and saline, the placenta is not delivered, manual extraction of the placenta should be offered as the definitive treatment. (No formal assessment of quality of evidence. Strength of recommendation). A single dose of antibiotics (ampicillin or first-generation cephalosporin) should be offered after manual removal of the placenta.

Despite scant evidence it is commonly advised that if the has not been expelled 30 minutes after delivery despite active management, MROP should be carried out under anesthesia. In the all so far published literature timing for manual removal depends on facilities available for MROP and presence or absence of PPH. ${ }^{20,21}$

The 2007 UK guidelines of National Institute of Clinical Excellence suggests 30 minutes whereas the WHO manual for childbirth suggests $60 \mathrm{~min}$. According, a survey in Europe showed that time until manual removal of placenta in the absence of bleeding varies widely between different countries from under 30 minutes (spain and hungry) to 60 minutes and more (The Netherlands).

NHS Clinical Guidelines for management of retained placenta and postpartum hemorrhage states, if the placenta is undelivered after 30 minutes consider empting bladder, breastfeeding or nipple stimulation, change of position -encourage upright position. ${ }^{16,19}$ Guidelines further states an intravenous oxytocin should not be used to assist the delivery of placenta unless there is bleeding. 
They do not recommend umbilical vein agents if the placenta is retained.

Adequate analgesia is given during examination. If a manual removal of placenta is required, it must be carried out under regional anesthesia. Documentation of third stage completion time and completeness of placenta has to be done. Senior persons -obstetrician and anesthetist should be called, secure $\mathrm{i} / \mathrm{v}$ line and give $40 \mathrm{u}$ oxytocin in $500 \mathrm{ml}$ Hartmann solution at rate of $125 \mathrm{ml} / \mathrm{hr}$. Measure blood loss accurately and manual removal of placenta if requires should be done in the operation theatre. Consultant present should be stipulated if there is any risk of adherent placenta or an anterior low-lying placenta with a previous history of cesarean section. Prophylactic antibiotic should be given, and surgeon should ensure complete removal of placenta.

If placenta is thought to be adherent, immediately seek opinion of senior obstetrician. Be aware of risk of uterine perforation. If constriction ring is present, then stop oxytocin drip to relax the uterus for easy insertion of hand and restart the drip soon after placental removal. Tocolytic agents can also be used. Patients with history of retained placenta and required manual removal of placenta are at a high risk of having $\mathrm{PPH}$ in future pregnancy so they are recommended to deliver at wellequipped obstetric unit during future pregnancy.

\section{CONCLUSION}

Complications which occurred during third stage of labor were perineal tear 4\% (37/899 deliveries). Atonic PPH occurred in $0.5 \%$ (9/899 deliveries). Traumatic PPH was $1.44 \%$ (13/899 deliveries and $0.3 \%$ cases had retained placenta. The third stage complications occurred in $6.4 \%$ of all vaginal deliveries. So perineal tears and traumatic PPH due to cervical tears had maximum occurrence. Both complications had big size babies (92\%) and (70\%) respectively as associated condition.

\section{ACKNOWLEDGMENTS}

Authors are thankful to all faculties colleague, post graduate residents and labor room staff for their support.

Funding: No funding sources Conflict of interest: None declared

Ethical approval: Obtained from Institutional Research and Ethics Committee

\section{REFERENCES}

1. AICOG Manual of Operative Obstetrics and postparturtum hemorrhage. In Birth injuries to lower birth canal Patel B, Shah A, Jani S. First Edition. Jaypee Brothers Medical Publishers; 2017:97-112.

2. National Health portal, India. Available at: https://www.nhp.gov.in/disease/gynaecology-andobstetrics/postpartum-haemorrhage
3. Estimates of Maternal Mortality Ratios in India and its States A Pilot Study; Institute for Research in Medical Statistics. Indian Council of Medical Research. July 2003.

4. SOGC clinical Practice Guideline. Active Management of the third stage of labour: Prevention and Treatment of Postpartum Hemorrhage. J Obstet Gynaecol Can. 2009;31(10):980-93.

5. Patel MM, Jain M. A study on active management of third stage of labor as per WHO Guidelines: efficacy and complications. Int $\mathbf{J}$ Reprod Contracept Obstet Gynecol. 2016Jan;5(1):80-3.

6. Maughan KL, Heim SW, Galazka SS. Preventing postpartum hemorrhage: managing the third stage of labor. Am Fam Physician. 2006;73(6):1025-8.

7. Ott J, Gritsch E, Pils S, Kratschmar S, Promberger R, Seemann $\mathrm{R}$, et al. A retrospective study on perineal lacerations in vaginal delivery and the individual performance of experienced mifwives. BMC pregnancy and childbirth. $2015 \mathrm{Dec} ; 15(1): 270$.

8. Smith LA, Price N, Simonite V, Burns EE. Incidence of and risk factors for perineal trauma: a prospective observational study. BMC Pregnancy Childbirth. 2013:13:59.

9. Suto M, Takehara K, Misago C, Matsui M. Prevalence of Perineal Lacerations in Women Giving Birth at Midwife-Led Birth Centers in Japan: A Retrospective Descriptive Study. J Midwifery Womens Health. 2015 Jul-Aug;60(4):419-27. doi 10.1111/jmwh.12324

10. Schmitz T, Alberti C, Andriss B, Moutafoff C, Oury JF, Sibony O. Identification of women at high risk for severe perineal lacerations. Eur $\mathbf{J}$ Obstet Gynaecol Repro Biol. 2014 Nov;182:11-5.

11. Hsieh WC, Liang CC, Wu D, Chang SD, Chueh HY, Chao AS. Prevalence and contributing factors of severe perineal damage following episiotomyassisted vaginal delivery. Taiwan J Obstet Gynecol. 2014 Dec 1;53(4):481-5.

12. Aasheim V, Nilsen ABV, Reinar LM, Lukasse M. Perineal techniques during the second stage of labour for reducing perineal trauma. Cochrane Database Syst Rev. $2017 \quad$ Jun;6:CD006672.doi 10.1002/14651858.CD006672.pub3

13. Ngwenya S. Postpartum hemorrhage: incidence, risk factors, and outcomes in a low-resource setting. International journal of women's health. 2016;8:647.

14. WHO 2012 Recommendations for the Prevention and treatment of Postpartum Hemorrhage. Available at

http://apps.who.int/iris/bitstream/handle/10665/7541 1/9789241548502_eng.pdf;jsessionid=866F8B2F71 B917B9A9CE922D484CDA9B? sequence $=1$. Assesse d on 6th April 2018

15. WHO guidelines for the mangement of Post-partum Haemorrhage and Retained Placenta. 2009.

16. NHS Clinical Guidelines: Postpartum Hemorrhage. Registration number o4234, June 2015.

17. WHO Recommendations: Intrapartum care for a positive child birth experience. Web annex. Evidence 
base. Geneva :World Health Organization ;2018(WHO/RHR/18.04)Licence :CCBY-NCSA3.0 IGO

18. Managing complications in pregnancy and childbirth: a guide for midwives and doctors. Geneva, World Health Organization ,2007.

19. NHS Clinical Guidelines: Management of retained Placenta. Registration number 04245, July 2015.

20. Intrapartum care. Care for healthy women and their babies during childbirth. National Institute for Health and Clinical Excellence, 2007. Available at http;//www.nice.org.uk/nicemedia/live/11837/36280/ 36280.pdf

21. Urner F, Zimmermann R, Krafft A. Manual removal of the placenta after vaginal delivery: an unsolved problem in obstetrics. J Preg. 2014;2014.

Cite this article as: Agarwal T, Kalra R, Suryawanshi A. Evaluation of complications during third stage of labour among women delivering at tertiary care center. Int J Reprod Contracept Obstet Gynecol 2018;7:xxx-Xx. 